Journal of Organometallic Chemistry, 127 (1977) 93-103

(O) Elsevier Sequoia S.A., Lausanne - Printed in The Netherlands

\title{
REACTION PATTERNS OF CYCLOPENTADIENYLCOBALT(I) CARBONYL AND ACETYLENE DERIVATIVES
}

WAI- SUN LEE * and HANS H. BRINTZINGER **

Department of Chemistry, The University of Michigan, Ann Arbor, Michigan 48104 (U.S.A.) and Fachbereich Chemie, Universität Konstanz, D 7750 Konstanz (West Germany)

(Received July 19th, 1976)

\section{Sụmmary}

Studies have been made of photochemical and thermal reaction sequences through which bisubstituted acetylenes are transformed in $\left(\mathrm{C}_{5} \mathrm{H}_{5}\right)$ Co-carbonyl reaction systems into cyclobutadiene and cyclopentadienone complexes and hexasubstituted benzenes. A primary intermediate observed by its IR spectrum in low-temperature photochemical reactions of $\left(\mathrm{C}_{5} \mathrm{H}_{5}\right) \mathrm{Co}(\mathrm{CO})_{2}$ with diphenyl alkynes $\mathrm{RC} \equiv \mathrm{CR}$ is the mixed mononuclear species $\left(\mathrm{C}_{5} \mathrm{H}_{5}\right) \mathrm{Co}(\mathrm{CO})(\mathrm{RC} \equiv \mathrm{CR})$. At room temperature this species is converted by excess alkyne into the cyclopentadienone complex $\left(\mathrm{C}_{5} \mathrm{H}_{5}\right) \mathrm{Co}\left(\mathrm{R}_{4} \mathrm{C}_{4} \mathrm{CO}\right)$. We have isolated from these reactions systems an important intermediate the mixed binuclear compound $\left(\mathrm{C}_{5} \mathrm{H}_{5}\right)_{2} \mathrm{Co}_{2}(\mu$ $\mathrm{CO})(\mathrm{RC} \equiv \mathrm{CR})$. In the presence of excess alkyne this compound is thermally converted either to the cyclobutadiene or to the cyclopentadienone complex of $\left(\mathrm{C}_{5} \mathrm{H}_{5}\right) \mathrm{Co}$, depending on the partial pressure of $\mathrm{CO}$ in the reaction system. The mixed binuclear compound forms a catalyst for the cyclotrimerization of excess 2-butyne. The fluxional binuclear metallocycle $\left(\mathrm{C}_{5} \mathrm{H}_{5}\right)_{2} \mathrm{Co}_{2}\left[\left(\mathrm{CH}_{3}\right)_{4} \mathrm{C}_{4}\right]$, which is formed by sodium amalgam reduction of $\left(\mathrm{C}_{5} \mathrm{H}_{5}\right) \mathrm{Co}(\mathrm{CO}) \mathrm{I}_{2}$ in the presence of 2-butyne, is a true catalyst for alkyne cyclotrimerization.

\section{Introduction}

The interaction of the cobalt carbonyl complex $\left(\mathrm{C}_{5} \mathrm{H}_{5}\right) \mathrm{Co}(\mathrm{CO})_{2}(1)$ with various substituted acetylenes gives a large number of products depending on the conditions and on the acetylene derivatives involved. Markby et al. first reported the formation of substituted cyclopentadienone complexes from reactions of 1 and dimethyl or diphenyl acetylene in sunlight [1]. A thermal reaction between

\footnotetext{
- Present address at Department of Chemistry. The University of Western Ontario, London (Canada).

* To whom correspondence should be addressed at Universitït Kanstanz. 7750 Konstanz (B.R.D.).
} 
the dicarbonyl 1 and hexafluoro-2-butyne was found to give an analogous tetrakis(trifluoromethyl)cyclopentadienone complex [2]. Subsequently, a variety of substituted cyclobutadiene and cyclopentadienone complexes were synthesized by thermal interaction of the dicarbonyl 1 and substituted alkynes [3].
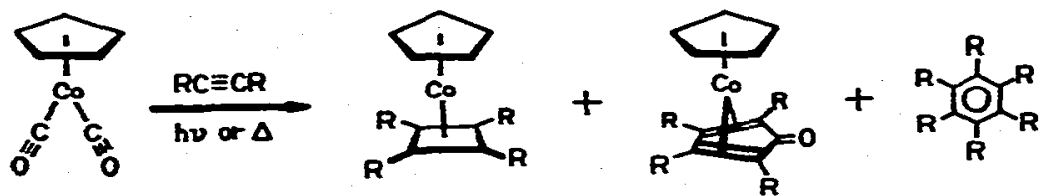

These reactions are sometimes accompanied by a cyclotrimerization of the alkyne reactant to the corresponding hexasubstituted benzene $[3,4]$. Similar cyclotrimerizations were observed by Wakatsuki and Yamazaki [5] to occur with incorporation of alkyl cyanides, leading to substituted pyridine derivatives. More recently, Bönnemann et al. [6] have developed this cocyclomerization reaction, catalyzed by 1 as well as by a number of other cobalt compounds, into a versatile synthetic method for a great variety of $N$-heterocyclic compounds.

We have tried to establish the nature of the basic reaction steps which occur in these reaction systems, and which by their relative rates determine the relative. yields of alternative products. In an extension of our previous studies on the reactive intermediates in the photolysis of 1 [7] we now report the observation of a number of intermediates and their interconversion reactions which occur in reaction systems involving the dicarbonyl compound 1 and dimethyl or diphenyl acetylenes.

\section{Results}

\section{Photolysis of $\left(\mathrm{C}_{5} \mathrm{H}_{5}\right) \mathrm{Co}(\mathrm{CO})_{2}$ in the presence of acetylenes}

In the absence of acetylenes, we observed species $2-5$ (Scheme 1 ) in irradiated solutions of the dicarbonyl 1 [7]. If the irradiation of 1 is carried out as before in toluene or petroleum ether solution at $-78^{\circ} \mathrm{C}$, but in the presence of an excess of diphenylacetylene, after $3-5 \mathrm{~h}$ several additional IR absorptions appear which differ from those observed for species 2-5. Most notably, a novel terminal $\mathrm{CO}$ band appears at $1990 \mathrm{~cm}^{-1}$. This species is unstable at room temperature and we were not able to isolate it and characterize it further. The terminal nature of its $\mathrm{CO}$ group indicates that this species is probably a mixed mononuclear complex $\left(\mathrm{C}_{5} \mathrm{H}_{5}\right) \mathrm{Co}(\mathrm{CO})(\mathrm{RC} \equiv \mathrm{CR})\left(6, \mathrm{R}=\mathrm{C}_{6} \mathrm{H}_{5}\right)$. At room temperature this species disappears, and a species with a $\nu(C O)$ band at about $1800 \mathrm{~cm}^{-1}$ remains as the thermally stable product. In addition, several absorption bands are observed at lower frequencies.

Isolation of these stable reaction products was achieved by column chromatography of the photolysis reaction mixture in toluene and subsequent recrystallization and sublimation. A green material, sublimable at $80^{\circ} \mathrm{C}$ and $10^{-3}$ torr was identified as the dinuclear acetylene carbonyl $\left(\mathrm{C}_{5} \mathrm{H}_{5}\right)_{2} \mathrm{Co}_{2}(\mu-\mathrm{CO})(\mathrm{RC} \equiv \mathrm{CR})(7$, $\mathrm{R}=\mathrm{C}_{6} \mathrm{H}_{5}$ ) by its IR absorption at $1800 \mathrm{~cm}^{-1}$ and by its NMR and mass spectra *.

- An analogous complex $\left(\mathrm{C}_{5} \mathrm{~F}_{5}\right)_{2} \mathrm{Co}_{2}\left(\mathrm{CO}_{2}\left(\mathrm{CH}_{3}\right)_{3} \mathrm{SiC} \equiv \mathrm{CSi}\left(\mathrm{CH}_{3}\right)_{3}\right]$ has recently been reported as a possible intermediate in the formation of a cyclobutadiene complex 10 with $\mathrm{R}=\mathrm{Si}\left(\mathrm{CH}_{3}\right)_{3}[8]$. 
A second brown fraction was found to contain the trinuclear acetylene carbonyl complex $\left(\mathrm{C}_{5} \mathrm{H}_{5}\right)_{3} \mathrm{Co}_{3}(\mu-\mathrm{CO})(\mu-\mathrm{RC} \equiv \mathrm{CR})\left(8, \mathrm{R}=\mathrm{C}_{6} \mathrm{H}_{5}\right)$. This compuund shows a strong absorption band at $1675 \mathrm{~cm}^{-1}$ and a weaker one at $1592 \mathrm{~cm}^{-1}$, attributable to triply coordinated $\mathrm{CO}$ and acetylene ligands, respectively.

In addition, the tetrasubstituted cyclopentadienone complex $\left(\mathrm{C}_{5} \mathrm{H}_{5}\right) \mathrm{Co}$ $\left(\mathrm{C}_{4} \mathrm{R}_{4} \mathrm{C}=\mathrm{O}\right)\left(9, \mathrm{R}=\mathrm{C}_{6} \mathrm{H}_{5}\right)$ [3], as well as smaller amounts of other, unidentified coordination compounds were observed among the products of the low-temperature photoreaction.

For the reaction steps connecting intermediates and products obser $2 \mathrm{~s}$ in this reaction system we propose the sequences shown in Scheme 1. The mononuclear acetylene carbonyl 6 undoubtedly arises from an attack of diphenylacetylene either on the primary photoproduct $\left(\mathrm{C}_{5} \mathrm{H}_{5}\right) \mathrm{Co}(\mathrm{CO})$ or on its dinuclear adduct 5 . This unstable intermediate 6 then gives two alternative products; in a dark reaction at room temperature in the presence of excess diphenylacetylene, the decay of 6 is associated with an increase of the cyclopentadienone (9) absorption at $1590 \mathrm{~cm}^{-1}$. Decay of 6 , particularly under photolysis conditions, could also be the source of the stable dinuclear acetylene carbonyl 7 . This latter species, might alternatively, arise from an attack of acetylene on the dinuclear carbonyls 4 or 5 , as discussed below.

For the trinuclear acetylene carbonyl complex 8 , we observe that irradiation of the trinuclear carbonyl 2 at $-78^{\circ} \mathrm{C}$ in the presence of diphenylacetylene gives 8 in reasonable yields. This trinuclear tricarbonyl is thus probably a precursor of the product $\left(\mathrm{C}_{5} \mathrm{H}_{5}\right)_{3} \mathrm{Co}_{3}(\mathrm{CO})(\mathrm{RC} \equiv \mathrm{CR})(8)$ under our conditions.

Further observations establish that a critical intermediate, whose alternative reactions with diphenylacetylene govern the product distribution according to eq. 1 , is the dinuclear acetylene carbonyl compound 7 . While solutions of 7 are stable towards acetylenes or carbon monoxide at room temperature, 7 is converted by an excess of diphenylacetylene in refluxing toluene either into the cyclopentadienone complex 9 or into the cyclobutadiene complex $\left(\mathrm{C}_{5} \mathrm{H}_{5}\right) \mathrm{Co}$ $\left(\mathrm{C}_{4} \mathrm{R}_{4}\right)\left(10, R=\mathrm{C}_{6} \mathrm{H}_{5}\right)$ [3]. If this reaction is carried out in an open system and thus purged of free $\mathrm{CO}$, one obtains the cyclobutadiene complex 10 almost exclusively, together with hexaphenylbenzene. Under an atmosphere of $\mathrm{CO}$, however, the cyclopentadienone 9 is formed in about $15 \%$ yield. Probably, the dinuclear complex 7 is cleaved by acetylene at the reaction temperature. The further course of the reaction is then determined by the likelihood of CO displacement by a second acetylene molecule and subsequent cyclodimerization, as opposed to persistence of the carbonyl ligand in a mixed acetylene carbonyl complex which, through an associative reaction with additional acetylene, forms the cyclopentadienone product 9 .

\section{Reduction of $\left(\mathrm{C}_{5} \mathrm{H}_{5}\right) \mathrm{Co}(\mathrm{CO}) \mathrm{I}_{2}$ in the presence of acetylenes}

In our previous study on the occurrence of reactive cyclopentadienylcobalt(I) derivatives, we observed that the dinuclear dicarbonyl compound $\left(\mathrm{C}_{5} \mathrm{H}_{5}\right)_{2} \mathrm{CO}_{2}-$ $(\mathrm{CO})_{2}(4)$ can be made by sodium amalgam reduction of $\left(\mathrm{C}_{5} \mathrm{H}_{5}\right) \mathrm{Co}(\mathrm{CO}) \mathrm{I}_{2}$ in a toluene solution at room temperature [7]. If such a reduction reaction is carried out in the presence of diphenylacetylene the dinuclear acetylene carbonyl complex 7 is obtained as the main product, together with significant amounts of the dicarbonyl 1, and smaller yields of the trinuclear carbonyl acetylene com- 
plex 8. The formation of the dinuclear complex 7 is consistent with an attack by diphenylacetylene on the dinuclear dicarbonyl 4 , the previously established product of this reduction reaction. The intermediacy of the mononuclear acetylene carbonyl 6 in this reaction is unlikely. We know that 6 would primarily yield the cyclopentadienone 9 in the presence of excess acetylene at ambient temperature but this product is not obtained in detectable amounts in the pressent reaction system.

If the reduction of $\left(\mathrm{C}_{5} \mathrm{H}_{5}\right) \mathrm{Co}(\mathrm{CO}) \mathrm{I}_{2}$ is carried out in the presence of 2-butyne in place of diphenylacetylene, one obtains, together with the dicarbonyl 1 , the compound $\left(\mathrm{C}_{5} \mathrm{H}_{5}\right)_{2} \mathrm{Co}_{2}\left(\mathrm{C}_{4} \mathrm{R}_{4}\right)\left(11, \mathrm{R}=\mathrm{CH}_{3}\right)$, instead of the dinuclear acetylene carbonyl obtained with diphenylacetylene. Complex $11(R=H)$ was obtained previously by irradiation of $\left(\mathrm{C}_{5} \mathrm{H}_{5}\right) \mathrm{Co}(\mathrm{CO})_{2}$ in the presence of photo- $\alpha$-pyrone [9]. The dark green tetramethyl complex obtained here is structurally fluxional, just as its $\mathbf{R}=\mathbf{H}$ analogue [9]. It contains a metallocyclopentadiene ring, which is $\eta$-coordinated to a second $\left(\mathrm{C}_{5} \mathrm{H}_{5}\right)$ Co unit. Both $\left(\mathrm{C}_{5} \mathrm{H}_{5}\right)$ Co units rapidly interchange their positions (in the plane of the $C_{4} R_{4}$ unit and perpendicular to it, respectively) probably by a libration of the $C_{4} R_{4}$ unit. From the temperaturedependence of its NMR spectrum in toluene- $d_{8}$, we find that this $1.4-\sigma \rightleftharpoons \eta^{4}$ shift has an activation energy of $19.2 \mathrm{kcal} / \mathrm{mol}$ and an activation entropy of 2.04 $\mathrm{eu}$; these data are in line with the intramolecular rearrangement proposed by Rosenblum et al. for the unsubstituted analogue [9]. Exposure of the tetramethyl complex $11\left(\mathrm{R}=\mathrm{CH}_{3}\right)$ to $\mathrm{CO}$ transforms it readily into about equal amounts of the dicarbonyl 1 and cyclopentadienone $\mathrm{g}\left(\mathrm{R}=\mathrm{CH}_{3}\right)$. This reaction indicates that 11 can be cleaved by ligand molecules in an unsymmetrical fashion into its unsaturated subunits $\left(\mathrm{C}_{5} \mathrm{H}_{5}\right) \mathrm{Co}\left(1.4-\sigma-\mathrm{C}_{4} \mathrm{R}_{4}\right)$ and $\left(\mathrm{C}_{5} \mathrm{H}_{5}\right) \mathrm{Co}$.

The different products obtained in the reduction of $\left(\mathrm{C}_{5} \mathrm{H}_{5}\right) \mathrm{Co}(\mathrm{CO}) \mathrm{I}_{2}$ in the presence of the two different acetylenes can be rationalized by the assumption that a common intermediate, obtained by attack of the respective acetylene on the dinuclear dicarbonyl 4, has alternative reaction paths available. For diphenylacetylene formation of an acetylene bridge under extrusion of one CO ligand appears to be favoured, whereas for 2-butyne the favoured reaction involves extrusion of the dicarbonyl 1 from the reaction complex. The remaining 2-butyne complex is then converted into the dinuclear metallocycle 11, a structure which is possibly unattainable for steric or electronic reasons for the phenyl-substituted analogue *.

\section{Cyclotrimerization of acetylenes}

A final point to be clarified with respect to equation 1 is the frequent observation of acetylene trimerization to hexasubstituted benzenes in $\left(\mathrm{C}_{5} \mathrm{H}_{5}\right)$ Co-based reaction systems $[3,4]$.

We find that the metallocyclic compound 11 acts as a catalyst for cyclotrimerization. When 2-butyne in toluene is heated to $110^{\circ} \mathrm{C}$ in the presence of small amounts of the metallocyclic complex 11, after a reaction time of $36 \mathrm{~h}$ and subsequent removal of solvent at room temperature, about 15 equivalents

- A corresponding rhodium complex with $R=\mathrm{C}_{6} \mathrm{H}_{5}$ has recently been isolated and characterized [10]. which sugrests steric crowding to be the cause of the absence of such a structure for the smaller cobalt atom. 
of hexamethylbenzene are obtained per equivalent of complex 11 used. The metallocyclic complex 11 is recovered quantitatively and appears to be the only cobalt-containing species present. In the presence of an excess of diphenylacetylene, the tetramethyl complex 11 forms largely hexaphenylbenzene and mainly the tetraphenylcyclobutadiene complex 10 is recovered.

An even more reactive catalyst than the metallocyclic complex 11 is formed from the diphenylacetylene carbonyl complex 7 . With an excess of 2-butyne in toluene at $110^{\circ} \mathrm{C}$, it produces copious amounts of hexamethylbenzene, and a mixed cyclopentadienone complex 12, (cyclopentadienyl)-2-5n-(2,3-dimethyl4,5-diphenyl)cyclopentadienonecobalt(1) can be isolated. Reaction of 7 with diphenylacetylene produces some hexaphenylbenzene, as mentioned above, but this reaction is never truly catalytic.

Apparently, conversion into the stable, inert tetraphenylcyclobutadiene compound $\mathbf{1 0}$ provides a more efficient trap for the catalytically active species in this case than with 2-butyne as a reactant.

\section{Discussion}

The results of these and the preceding studies [7] are summarized in Scheme 1 , where the top two lines represent the chemical and photochemical entries into the series of reactive carbonyl derivatives [7]. The next line down represents the acetylene-containing intermediates identified in the present study and the bottom line shows the stable reaction products previously reported $[3,4]$.

Our results do not enable us to make any definite statements on the nature of possible additional intermediates involved in the catalytic trimerization, but it is likely that some derivative of a metallocyclic structure $\left(\mathrm{C}_{5} \mathrm{H}_{5}\right) \operatorname{Co}\left(1.4 \sigma-\mathrm{C}_{4} \mathrm{R}_{4}\right)$ is involved in this catalysis (cf. ref. 11). In particular the question of whether the cyclization of acetylenes occurs on a single, mononuclear $\left(\mathrm{C}_{5} \mathrm{H}_{5}\right) \mathrm{Co}$ unit or whether several such units in a bi- or poly-nuclear cluster are involved in this acetylene cyclotrimerization remains to be clarified.

Some useful comparisons can be made with respect to the relative reactivities of analogous $\left(\mathrm{C}_{5} \mathrm{H}_{5}\right) \mathrm{Co}$ - and $\left(\mathrm{C}_{5} \mathrm{H}_{5}\right)_{2} \mathrm{Ti}$-derivatives. The dicarbonyl $\left(\mathrm{C}_{5} \mathrm{H}_{5}\right)_{2} \mathrm{Ti}(\mathrm{CO})_{2}$ can be thermally converted into a mixed acetylene carbonyl complex $\left(\mathrm{C}_{5} \mathrm{H}_{5}\right)_{2} \mathrm{Ti}$ $(\mathrm{CO})(\mathrm{RC} \equiv \mathrm{CR})$ [12]. While this complex is quite reactive as a catalyst for acetylene hydrogenation [12], it appears to be fairly stable at room temperature when compared to its cobalt analogue $\left(\mathrm{C}_{5} \mathrm{H}_{5}\right) \mathrm{Co}(\mathrm{CO})(\mathrm{RC} \equiv \mathrm{CR})$, which is immediately converted at room temperature either into a dinuclear species or into the cyclopentadienone complex 9.

The mononuclear metallocycle $\left(\mathrm{C}_{5} \mathrm{H}_{5}\right)_{2} \mathrm{Ti}\left(1.4-\sigma-\mathrm{C}_{4} \mathrm{R}_{4}\right)$ is also quite stable at room temperature [13]. In contrast to its hypothetical cobalt analog $\left(\mathrm{C}_{5} \mathrm{H}_{5}\right) \mathrm{Co}$ (1.4- $\left.\sigma-\mathbf{C}_{4} \mathbf{R}_{4}\right)$, this 16-electron species does not tend to relieve its electron deficiency either by formation of binuclear aggregates nor by isomerization to an 18-electron cyclobutadiene structure. The higher tendency of coordinatively unsaturated $\left(\mathrm{C}_{5} \mathrm{H}_{5}\right)$ Co derivatives to complete their valence shell is probably a consequence of a decreased steric encumbrance of the cobalt half-sandwich structure as compared to the titanium sandwich, and of the higher number of essentially non-bonding electrons available on a Co-center for back-donation to unsaturated ligands. 
SCHEME 1

REACTION PATHWAYS IN ( -CYCLOPENTADIENYL)COBALT(I) REACTION SYSTEMS WITH CARBONYL AND ACETYLENE LIGANDS

Photochemical reactions are indicated by wavy arrow's: straight arrows signify themal reactions. intermediates with number given in square brackets were cbserved spectroscopically in solution only; all other compounds were isolated and characterized in this work or have been previously described in the literature: Me $=\mathrm{CH}_{3}, \theta=\mathrm{C}_{6} \mathrm{H}_{5}$; numbers in parentheses are carbonyl stretching frequencies in $\mathrm{cm}^{-1}$.

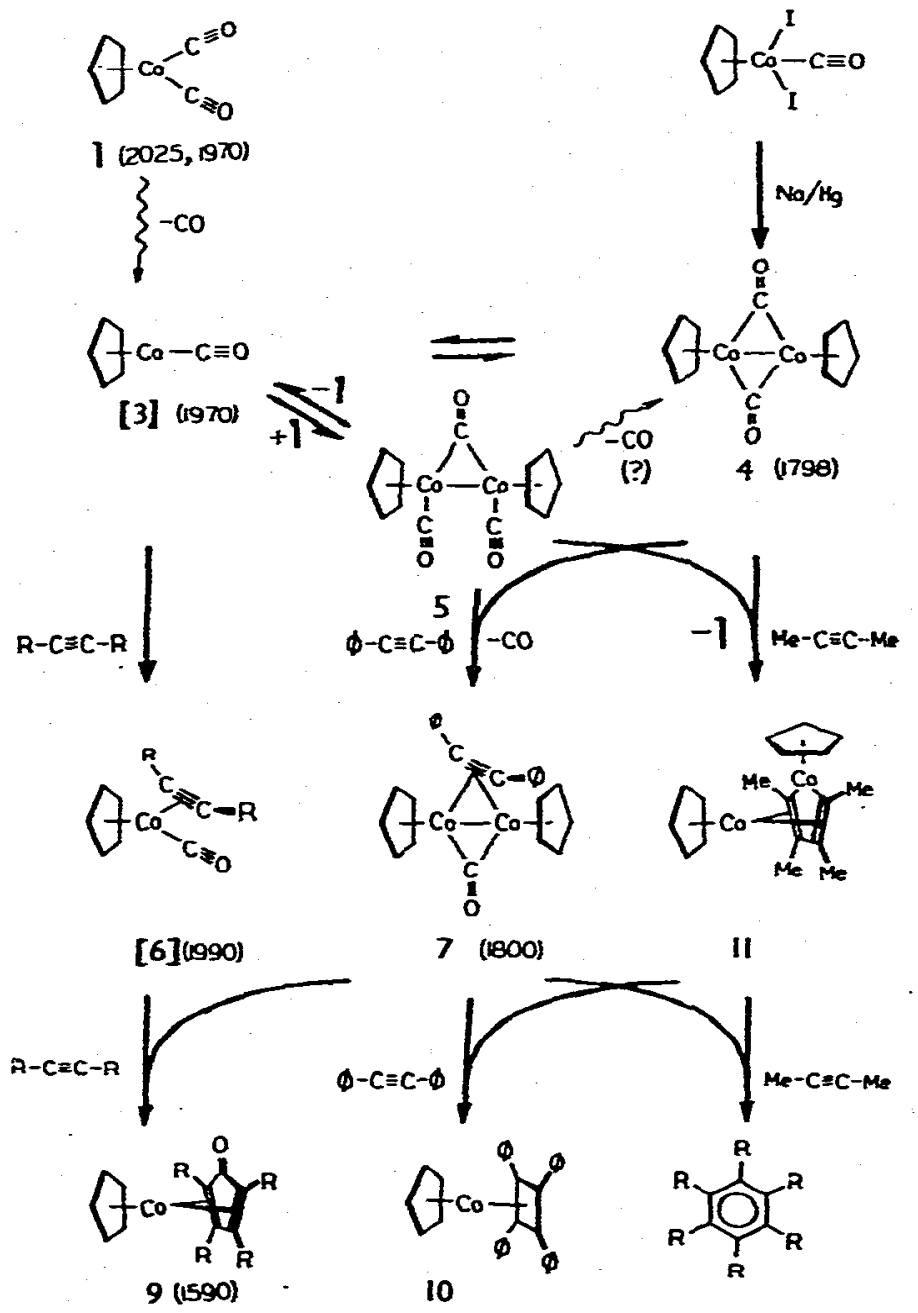

\section{Experimental section}

General techniques and chemicals

All manipulations of air-sensitive compounds were carried out under an inert gas atmosphere, using either Schlenk or high-vacuum manifold techniques.

Diphenylacetylene and octacarbonyldicobalt for the synthesis of $\left(\mathrm{C}_{5} \mathrm{H}_{5}\right) \mathrm{Co}$ - 
(CO) 2 were purchased from Fluka AG, Switzerland and 2-butyne and alumina were purchased from Chemicals Procurement Laboratories Inc. (U.S.A.) and Merck (Germany), respectively. All solvents were doubly distilled and dried with butyllithium or methyllithium.

\section{Instruments}

IR spectra were taken on an Shimadzu 400 spectrophotometer, proton magnetic resonance measurements with a JEOL-MH-100 high resolution spectrometer, and mass spectra on a Varian $\mathrm{CH} 7$ mass spectrometer.

\section{Photoreaction of $\left(\mathrm{C}_{5} \mathrm{H}_{5}\right) \mathrm{Co}(\mathrm{CO})_{2}$ with diphenylacetylene at $-78^{\circ} \mathrm{C}$}

A toluene solution $(200 \mathrm{ml})$ of $\left(\mathrm{C}_{5} \mathrm{H}_{5}\right) \mathrm{Co}(\mathrm{CO})_{2}(0.7 \mathrm{ml}, 5.44 \mathrm{mmol})$ and diphenylacetylene $(1.3 \mathrm{~g}, 7.30 \mathrm{mmol})$ was irradiated at $-78^{\circ} \mathrm{C}$ for $4 \mathrm{~h}$, while nitrogen was bubbled through. IR spectra of this solution were obtained after varying irradiation periods by quickly transferring a sample to a $0.5 \mathrm{~mm}$ solution IR cell. Changes in these IR spectra vere followed at room temperature over a period of several hours. After an irradiation time of $3-5 \mathrm{~h}$, the solution was concentrated to about $30 \mathrm{ml}$ and chromatographed on a column of alumina. Four bands, in the sequence reddish-orange, dark green, dark brown, and red, were observed on the column. Low-boiling petroleum ether $\left(50-70^{\circ} \mathrm{C}\right)$ was first used as the eluent for the reddish-orange band. It was identified as unchanged $\left(\mathrm{C}_{5} \mathrm{H}_{5}\right) \mathrm{Co}(\mathrm{CO})_{2}$ by its IR spectrum. Toluene eluted the dark green and dark brown bands, identified as $\left(\mathrm{C}_{5} \mathrm{H}_{5}\right)_{2} \mathrm{Co}_{2}(\mu-\mathrm{CO})\left(\mu-\mathrm{C}_{6} \mathrm{H}_{5} \mathrm{C} \equiv \mathrm{CC}_{6} \mathrm{H}_{5}\right)(7)$ and $\left(\mathrm{C}_{5} \mathrm{H}_{5}\right)_{3} \mathrm{Co}_{3}(\mu-\mathrm{CO})\left(\mathrm{C}_{6} \mathrm{H}_{5} \mathrm{C}\right.$ $\left.\equiv \mathrm{CC}_{6} \mathrm{H}_{5}\right)(8)$, respectively. A purified sample of $\left(\mathrm{C}_{5} \mathrm{H}_{5}\right)_{2} \mathrm{Co}_{2}(\mu-\mathrm{CO})\left(\mathrm{C}_{6} \mathrm{H} \mathrm{H}_{5} \equiv \mathrm{CC}_{6} \mathrm{H}_{5}\right)$ was obtained by vacuum sublimation at $80^{\circ} \mathrm{C}$. Its IR spectrum exhibits a strong absorption peak at $1800 \mathrm{~cm}^{-1}$ in Nujol (or cyclohexane), attributed to the stretching vibration of a bridging carbonyl group. Its proton spectrum in toluene$d_{8}$ shows two broad multiplets, centered at $\tau 2.63$ and 2.16 and a sharp singlet at $\tau 5.30 \mathrm{ppm}$ with the intensity ratios $2: 3: 5$. Its molecular weight was determined as $\mathbf{4 5 4}$ by mass spectrometry. The observation of prominent fragment ions for loss of $\mathrm{CO}(\mathrm{m} / \mathrm{e} 426),\left(\mathrm{C}_{5} \mathrm{H}_{5}\right) \mathrm{Co}(\mathrm{CO})(\mathrm{m} / \mathrm{e} 302)$, and $\left(\mathrm{C}_{5} \mathrm{H}_{5}\right)_{2} \mathrm{Co}(\mathrm{m} / \mathrm{e} 265)$, in addition to the ions $\left(\mathrm{C}_{5} \mathrm{H}_{5}\right)_{2} \mathrm{Co}^{+}$and $\left(\mathrm{C}_{5} \mathrm{H}_{5}\right) \mathrm{Co}^{+}(\mathrm{m} / \mathrm{e}$ 124), together with a number of characteristic metastable peaks establish the identity of this material. A fair amount of $\left(\mathrm{C}_{5} \mathrm{H}_{5}\right)_{3} \mathrm{Co}_{3}(\mu-\mathrm{CO})\left(\mathrm{C}_{6} \mathrm{H}_{5} \mathrm{C} \equiv \mathrm{CC}_{6} \mathrm{H}_{5}\right)(8)$ and some (cyclopentadienyl)-2-5n-(2,3,4,5-tetraphenyl)cyclopentadienonecobalt (9) were also eluted from the chromatography column by toluene and chloroform, respectively. Their identities were confirmed by IR and mass spectra. Yields: $\left(\mathrm{C}_{5} \mathrm{H}_{5}\right)_{2} \mathrm{Co}_{2}(\mu-\mathrm{CO})$ $\left(\mathrm{C}_{6} \mathrm{H}_{5} \mathrm{C} \equiv \mathrm{CC}_{6} \mathrm{H}_{5}\right)(8) 0.55 \mathrm{mmol}(20.24 \%),\left(\mathrm{C}_{5} \mathrm{H}_{5}\right)_{3} \mathrm{Co}_{3}(\mu-\mathrm{CO})\left(\mathrm{C}_{6} \mathrm{H}_{5} \mathrm{C} \equiv \mathrm{CC}_{6} \mathrm{H}_{5}\right)(8)$ $1.04 \mathrm{mmol}(57.35 \%)$ and $\left(\mathrm{C}_{5} \mathrm{H}_{5}\right) \mathrm{Co}\left(\eta^{4}-\mathrm{C}_{4}\left(\mathrm{C}_{6} \mathrm{H}_{5}\right)_{4} \mathrm{C}=\mathrm{O}(9) 0.35 \mathrm{mmol}(6.5 \%)\right.$.

\section{Photoreaction of $\left(\mathrm{C}_{5} \mathrm{H}_{5}\right)_{3} \mathrm{Co}_{3}(\mathrm{CO})_{3}$ (2) with diphenylacetylene}

$\left(\mathrm{C}_{5} \mathrm{H}_{5}\right)_{3} \mathrm{Co}_{3}(\mathrm{CO})_{3}(0.12 \mathrm{~g}, 0.26 \mathrm{mmol})$ and diphenylacetylene $(0.2 \mathrm{~g}, 1.12$ mmol) were mixed in a photolysis vessel with about $150 \mathrm{ml}$ of dry toluene. The solution was photolyzed at $-78^{\circ} \mathrm{C}$ for $19 \mathrm{~h}$ while nitrogen was bubbled through. The dark solution was concentrated to about $20 \mathrm{ml}$ and chromatographed on a column of alumina (Merck), with toluene as the eluent. A small amount of $\left(\mathrm{C}_{5} \mathrm{H}_{5}\right) \mathrm{Co}(\mathrm{CO})_{2}$, identified by its IR spectrum, was the first product obtained from the chromatography column. A brown portion was next collected. A pure 
compound of composition $\left(\mathrm{C}_{5} \mathrm{H}_{5}\right)_{3} \mathrm{Co}_{3}(\mu-\mathrm{CO})\left(\mu-\mathrm{C}_{6} \mathrm{H}_{5} \mathrm{C} \equiv \mathrm{CC}_{6} \mathrm{H}_{5}\right)(8)$ was obtained by recrystallization of the brown evaporation residue from petroleum ether. Its IR spectrum (KBr) shows a strong absorption peak at $1675 \mathrm{~cm}^{-1}$ and a weak peak at $1592 \mathrm{~cm}^{-1}$. The NMR spectrum (in $\mathrm{CDCl}_{3}$ ) exhibits a singlet at $\tau 5.35$ ppm $\left(\mathrm{C}_{5} \mathrm{H}_{5}\right)$ and two broad multiplets centered at $\tau 2.40$ and $2.66 \mathrm{ppm}$ (phenyl protons) in the intensity ratio of $15: 4: 6$. The NMR spectrum is temperatureinvariant down to $-65^{\circ} \mathrm{C}$. The mass spectrum of the complex shows a fairly intense parent molecular ion peak at $m / e$ 578. The first fragmentation step is a loss of the triply bonded carbonyl ligand, based on the observation of an ion peak at $m / e \mathbf{5 5 0}$ and a metastable peak ranging from mass unit 521 to 525 . Subsequent major ion currents at $m / e 370\left(\left(\mathrm{C}_{5} \mathrm{H}_{5}\right)_{3} \mathrm{Co}_{3}{ }^{+}-\mathrm{H}_{2}, 25.8 \%\right), 361\left(\left(\mathrm{C}_{5} \mathrm{H}_{5}\right)^{-}\right.$ $\left.\mathrm{Co}_{2}\left(\mathrm{C}_{6} \mathrm{H}_{5} \mathrm{C} \equiv \mathrm{CC}^{6} \mathrm{H}_{5}\right)^{+}, 10.6 \%\right)$ and $247\left(\left(\mathrm{C}_{5} \mathrm{H}_{5}\right)_{2} \mathrm{Co}_{2}{ }^{+}-\mathrm{H}, 15.9 \%\right)$ and a small amount of ion current at $118\left(\mathrm{Co}_{2}{ }^{+}, 4 \%\right)$ suggest the presence of cobalt-cobalt bonds.

From the original chromatography column, a last band was eluted with chloroform. The red solid obtained in small amounts after removal of solvent was identified as (cyclopentadienyl)-(2-57-(2,3,4,5-tetraphenyl)cyclopentadienone)cobalt (9) by its IR spectrum and mass spectra. The IR spectrum shows a strong absorption peak at $1590 \mathrm{~cm}^{-1}$, in accord with the literature [3]. Its mass spectrum shows the parent molecular ion at $m / e \mathbf{5 0 8}$ and subsequent fragments at $m / e 480,302,124$.

\section{Reaction of $\left(\mathrm{C}_{5} \mathrm{H}_{5}\right)_{2} \mathrm{Co}_{2}(\mu-\mathrm{CO})\left(\mu-\mathrm{C}_{6} \mathrm{H}_{5} \mathrm{C} \equiv \mathrm{CC}_{6} \mathrm{H}_{5}\right)(10)$ with diphenylacetylene}

(a) In an open system. A solution of $0.175 \mathrm{~g}(0.385 \mathrm{mmol})$ of $\left(\mathrm{C}_{5} \mathrm{H}_{5}\right)_{2} \mathrm{Co}_{2}(\mu-$ $\mathrm{CO})\left(\mathrm{C}_{6} \mathrm{H}_{5} \mathrm{C}=\mathrm{CC}_{6} \mathrm{H}_{5}\right)(7)$ and $0.38 \mathrm{~g}(2.13 \mathrm{mmol})$ of diphenylacetylene in toluene was refluxed for two days at the boiling point of the solvent $\left(110^{\circ} \mathrm{C}\right)$ with the exit of the reflux condenser connected to an oil bubbler to allow escape of $\mathrm{CO}$ gas. Cooling to room temperature, evaporation and sublimation at $40^{\circ} \mathrm{C}$ yielded unreacted diphenylacetylene $(0.20 \mathrm{~g})$. The residue was then dissolved in about 20 $\mathrm{ml}$ of toluene and filtered from a gray residue of hexaphenylbenzene. The filtrate was chromatographed on a $50 \mathrm{~cm}$ column of Merck alumina with toluene as eluent, to give an orange solution. Evaporation gave a residue identified as ( $\eta$-cyclopentadienyl)( $\eta$-tetraphenylcyclobutadiene)cobalt by its mass spectrum. Yields: hexaphenylbenzene $0.087 \mathrm{mmol}$ (12.25\%), and ( $\eta$-cyclopentadienyl)( $\eta$-tetraphenylcyclobutadiene)cobalt, $0.602 \mathrm{mmol}(78.2 \%)$.

(b) Under carbon monoxide pressure. A solution of $\left(\mathrm{C}_{5} \mathrm{H}_{5}\right)_{2} \mathrm{Co}_{2}(\mu-\mathrm{CO})\left(\mathrm{C}_{6} \mathrm{H}{ }_{5} \mathrm{C} \equiv\right.$ $\left.\mathrm{CC}_{6} \mathrm{H}_{5}\right)(0.21 \mathrm{~g}, 0.463 \mathrm{mmol})$ and diphenylacetylene $(0.38 \mathrm{~g}, 2.13 \mathrm{mmol})$ in toluene $(30 \mathrm{ml})$ was syringed into a medium pressure glass reaction vessel with a Teflon stopcock, and one atmosphere of $\mathrm{CO}$ gas was introduced. The closed vessel was then heated to $110^{\circ} \mathrm{C}$ on an oil bath for two days. After cooling to room temperature, products were separated by the procedure described in section $3(a)$. Besides hexaphenylbenzene, and ( $\eta$-cyclopentadienyl)( $\eta$-tetraphenylcyclobutadiene)-cobalt, a red band was observed on the chromatography column ans eluted by chloroform. Evaporation of this red solution yielded a brick-red solid which was identified as ( $\eta$-cyclopentadienyl)-2-5n-(2,3,4,5-tetraphenyl)cyclopentadienonecobalt $\left(9, R=\mathrm{C}_{6} \mathrm{H}_{5}\right)$, by its characteristic IR absorption peak at $1590 \mathrm{~cm}^{-1}$ and its mass spectrum. The mass spectrum shows a parent molecular ion at $m / e 508$ and subsequent fragments at $m / e 480,302,124$ and 59 . Yields: 
hexaphenylbenzene $0.126 \mathrm{mmol}(17.8 \%)$, (cyclopentadienyl)( $\eta$-tetraphenylcyclobutadiene)cobalt (10) $0.606 \mathrm{mmol}(65.44 \%)$ and complex $9\left(R=C_{6} H_{5}\right) 0.114$ mmol (15.6\%).

\section{Reduction of $\left(\mathrm{C}_{5} \mathrm{H}_{5}\right) \mathrm{Co}(\mathrm{CO}) \mathrm{I}_{2}$ in the presence of diphenylacetylene}

$1.6 \mathrm{~g}(3.94 \mathrm{mmol})$ of $\left(\mathrm{C}_{5} \mathrm{H}_{5}\right) \mathrm{Co}(\mathrm{CO}) \mathrm{I}_{2}, 9 \mathrm{mmol}$ of sodium amalgam and 0.36 $\mathrm{g}(2.02 \mathrm{mmol})$ of diphenylacetylene in about $60 \mathrm{ml}$ toluene were stirred under vacuum. After 15 minutes, the purple solution changed to greenish-brown. In another 15 minutes, the solution became dark brown. The solution was kept stirring for $16 \mathrm{~h}$. A dark greenish-brown solution was obtained after filtration. The solution was concentrated to about $25 \mathrm{ml}$ and chromatographed on an alumina column. With petroleum ether $\left(50-70^{\circ} \mathrm{C}\right)$ as a first eluent; a reddishorange portion of $\left(\mathrm{C}_{5} \mathrm{H}_{5}\right) \mathrm{Co}(\mathrm{CO})_{2}$ was collected. By elution with toluene, two compounds were successively collected and identified as $\left(\mathrm{C}_{5} \mathrm{H}_{5}\right)_{2} \mathrm{Co}_{2}(\mu-\mathrm{CO})-$ $\left(\mathrm{C}_{6} \mathrm{H}_{5} \mathrm{C} \equiv \mathrm{CC}_{6} \mathrm{H}_{5}\right)(7)$ and $\left(\mathrm{C}_{5} \mathrm{H}_{5}\right)_{3} \mathrm{Co}_{3}(\mu-\mathrm{CO})\left(\mathrm{C}_{6} \mathrm{H}_{5} \mathrm{C} \equiv \mathrm{CC}_{6} \mathrm{H}_{5}\right)(8)$ by their spectroscopic data. Yields: $\left(\mathrm{C}_{5} \mathrm{H}_{5}\right) \mathrm{Co}(\mathrm{CO})_{2} 1.16 \mathrm{mmol}(29.44 \%),\left(\mathrm{C}_{5} \mathrm{H}_{5}\right)_{2} \mathrm{Co}_{2}(\mu-\mathrm{CO})-$ $\left(\mathrm{C}_{6} \mathrm{H}_{5} \mathrm{C} \equiv \mathrm{CC}_{6} \mathrm{H}_{5}\right)(7) 0.55 \mathrm{mmol}(27.95 \%)$ and $\left(\mathrm{C}_{5} \mathrm{H}_{5}\right)_{3} \mathrm{Co}_{3}(\mu-\mathrm{CO})\left(\mathrm{C}_{6} \mathrm{H}_{5} \mathrm{C} \equiv \mathrm{CC}_{6} \mathrm{H}_{5}\right)$ (8) $0.134 \mathrm{mmol}(10.21 \%)$.

\section{Reduction of $\left(\mathrm{C}_{5} \mathrm{H}_{5}\right) \mathrm{Co}(\mathrm{CO}) \mathrm{I}_{2}$ in the presence of 2-butyne}

A mixture of $\left(\mathrm{C}_{5} \mathrm{H}_{5}\right) \mathrm{Co}(\mathrm{CO}) \mathrm{I}_{2}(0.80 \mathrm{~g}, 1.97 \mathrm{mmol})$ and sodium amalgam (4.5 $\mathrm{mmol}$ ) in about $60 \mathrm{ml}$ toluene was stirred with excess 2-butyne. After $30 \mathrm{~min}$ utes, the purple solution changed to brownish-green. Stirring was continued for $10 \mathrm{~h}$ to ensure complete reaction. The solution was then filtered and concentrated to. $20 \mathrm{ml}$ for chromatography. Elution with toluene gave two bands, in the order red-orange and green. The red-orange material was identified as $\left(\mathrm{C}_{5} \mathrm{H}_{5}\right)$ $\mathrm{Co}(\mathrm{CO})_{2}$ by its IR spectrum and its concentration was quantitively determined by a calibrated concentration-absorbance curve of $\left(\mathrm{C}_{5} \mathrm{H}_{5}\right) \mathrm{Co}(\mathrm{CO})_{2}$.

The green solution was evaporated to dryness under vacuum give a dark green solid, which was purified by vacuum sublimation at $40^{\circ} \mathrm{C}$. The mass spectrum of this material with a parent ion at $m / e$ establishes a composition $\left(\mathrm{C}_{5} \mathrm{H}_{5}\right)_{2} \mathrm{Co}_{2}$ $\left(\mathrm{C}_{4} \mathrm{R}_{4}\right)\left(11, \mathrm{R}=\mathrm{CH}_{3}\right)$.

The ${ }^{1} \mathrm{H}$ NMR spectrum of the complex in benzene- $d_{6}$ at room temperature exhibits four sharp singlets at $\tau 5.66,5.27\left(\mathrm{C}_{5} \mathrm{H}_{5}\right), 7.47$ and $8.36 \mathrm{ppm}-\left(\mathrm{CH}_{3}\right)$ with the intensity ratio of $5: 5: 6: 6$. Its IR spectrum (Nujol) shows the following major absorption peaks: $1410 \mathrm{w}, 1350 \mathrm{w}, 1330 \mathrm{w}, 1180 \mathrm{~m}, 1105 \mathrm{~m}$ (with a shoulder at lower frequency), 1082w, 1045m, 1018w, 998s, 905w, 880w, $835 \mathrm{~m}$, 814 s (with a lower frequency shoulder) and 782s. No carbonyl absorption is observed in the spectrum. On the basis of this data, we assign to this complex structure 11, which is analogous to that of a previously reported complex $\left(\mathrm{C}_{5} \mathrm{H}_{5}\right)_{2} \mathrm{Co}_{2}-$ $\left(\mathrm{C}_{4} \mathrm{H}_{4}\right)$ [9]. Similar to this latter complex, 11 is fluxional: In the temperature range $70-120^{\circ} \mathrm{C}$ the $\mathrm{C}_{5} \mathrm{H}_{5}$ signals at $\tau 5.66$ and $5.27 \mathrm{ppm}$ coalesce; from each line shape function [14], fluxional life times $\Gamma$ are obtained for each temperature, a plot of $\log (\Gamma T)$ versus $1 / T$ yields the fluxional activation energy of 19.16 $\mathrm{kcal} / \mathrm{mol}$ in toluene- $d_{8}$. The methyl signals at 7.47 and $8.35 \mathrm{ppm}$ are unaffected by temperature. Yields: $\left(\mathrm{C}_{5} \mathrm{H}_{5}\right) \mathrm{Co}(\mathrm{CO})_{2} 0.865 \mathrm{mmol}(87.8 \%)$ and complex 11 , $0.470 \mathrm{mmol}(95.5 \%)$. 
6. Reaction between $\left(\mathrm{C}_{5} \mathrm{H}_{5}\right)_{2} \mathrm{Co}_{2}\left(\mathrm{C}_{4} \mathrm{R}_{4}\right)\left(11, \mathrm{R}=\mathrm{CH}_{3}\right)$ and carbon monoxide

$\mathrm{CO}$ gas (3.1 mmol) was introduced into a toluene solution of $0.09 \mathrm{~g}(0.25$ mmol) of $11\left(\mathrm{R}=\mathrm{CH}_{3}\right)$. After stirring for about $10 \mathrm{~h} 2.8 \mathrm{mmol}$ of $\mathrm{CO} / \mathrm{mmol}$ of 11 had been taken up, and the green solution had changed to a yellowish-orange color. This solution contained $0.22 \mathrm{mmol}$ of $\left(\mathrm{C}_{5} \mathrm{H}_{5}\right) \mathrm{Co}(\mathrm{CO})_{2}$, determined by quantitative IR measurements. Vacuum distillation removed the solvent and $\left(\mathrm{C}_{5} \mathrm{H}_{5}\right) \mathrm{Co}(\mathrm{CO})_{2}$ from the solution, and the remaining orange solid was sublimed at $45-50^{\circ} \mathrm{C}$ under vacuum. It was characterized as complex $9\left(\mathrm{R}=\mathrm{CH}_{3}\right)$ by the following spectroscopic data. Mass spectrum: $m / e 260\left(M^{+}, 100 \%\right), 232\left(M^{*}-C O_{\text {; }}\right.$ 6.9\%), $231\left(M^{+}-\mathrm{CO}-\mathrm{H}, 20.7 \%\right), 217\left(M^{+}-\mathrm{CO}-\mathrm{CH}_{3}, 48.4 \%\right), 124\left(\mathrm{C}_{5} \mathrm{H}_{5} \mathrm{Co}\right.$, $55.2 \%)$. ' $\mathrm{H}$ NMR: three sharp singlets at $\tau 5.84,8.35$ and $8.50 \mathrm{ppm}$ in the intensity ratio of $5: 6: 6$. IR spectrum: A strong absorption peak at $1580 \mathrm{~cm}^{-1}$, characteristic of a coordinated cyclopentadienone ligand. Yields: $\left(\mathrm{C}_{5} \mathrm{H}_{5}\right) \mathrm{Co}(\mathrm{CO})_{2}$ $0.22 \mathrm{mmol}(88.0 \%)$ and, complex $9\left(\mathrm{R}=\mathrm{CH}_{3}\right) 0.23 \mathrm{mmol}(92 \%)$.

7. Cyclization of 2-butyne by $\left(\mathrm{C}_{5} \mathrm{H}_{5}\right)_{2} \mathrm{Co}_{2}(\mu-\mathrm{CO})\left(\mathrm{C}_{6} \mathrm{H}_{5} \mathrm{C} \equiv \mathrm{CC}_{6} \mathrm{H}_{5}\right)$ (7)

2-Butyne $(2.2 \mathrm{ml}, 28.15 \mathrm{mmol})$ was distilled into a toluene solution of $7(0.10$ $\mathrm{g}, 0.22 \mathrm{mmol}$ ) in the medium pressure reaction vessel mentioned above. The mixture was heated up to $110^{\circ} \mathrm{C}$ for $36 \mathrm{~h}$. White crystals appeared, and the originally green solution changed to brown. After cooling to $-78^{\circ} \mathrm{C}$, crystallization of most of the white material, and filtration, the brown solution was chromatographed on an alumina column and a reddish-orange solution was eluted with chloroform. The reddish-orange material was identified as complex 12 by its IR and mass spectra. Its IR spectrum exhibits a very strong absorption peak at $1593 \mathrm{~cm}^{-1}$, characteristic of a coordinated cyclopentadienone ligand. The ${ }^{1} \mathrm{H}$ NMR spectrum of the complex consists of a broad multiplet ( $\tau 2.32-2.92 \mathrm{ppm}$ ) and three singlets $(\tau 5.26,7.98$, and $8.06 \mathrm{ppm})$ with the intensity ratio of $10: 5: 3: 3$. Its mass spectrum shows ion currents at $m / e 384$ (parent molecular ion $\left.M^{+}, 70.33 \%\right), 383\left(M^{+}-\mathrm{H}, 100 \%\right), 369\left(M^{+}-\mathrm{CH}_{3}, 13.21 \%\right)$, and 124 $\left(\mathrm{C}_{5} \mathrm{H}_{5} \mathrm{Co}^{+}, 12.20 \%\right)$. Yield: hexamethylbenzene, $1.14 \mathrm{~g}(7.04 \mathrm{mmol})$.

8. Cyclization of 2-butyne by $\left(\mathrm{C}_{5} \mathrm{H}_{5}\right)_{2} \mathrm{Co}_{2}\left(\mathrm{C}_{4} \mathrm{R}_{4}\right)\left(11, \mathrm{R}=\mathrm{CH}_{3}\right)$

$6.5 \mathrm{ml}(83.18 \mathrm{mmol})$ of 2-butyne was distilled into a toluene solution of $\left(\mathrm{C}_{5} \mathrm{H}_{5}\right)_{2} \mathrm{Co}_{2}\left(\mathrm{C}_{4} \mathrm{R}_{4}\right)\left(11, \mathrm{R}=\mathrm{CH}_{3}\right)(0.08 \mathrm{~g}, 0.224 \mathrm{mmol})$ in the medium pressure reaction vessel. The mixture was refluxed for $36 \mathrm{~h}$. After cooling, hexamethylbenzene $(0.20 \mathrm{~g}, 1.23 \mathrm{mmol})$, identified by its mass and IR spectra, was sublimed under high vacuum at room temperature, and $0.08 \mathrm{~g}$ of unchanged green $\left(\mathrm{C}_{5} \mathrm{H}_{5}\right)_{2^{-}}$ $\mathrm{Co}_{2}\left(\mathrm{C}_{4} \mathrm{R}_{4}\right)\left(11, \mathrm{R}=\mathrm{CH}_{3}\right)$ was recovered by sublimation at $50^{\circ} \mathrm{C}$ under vacuum.

\section{Acknowledgements}

This work was supported by grants from the National Science Foundation (GP 33130X), from Fonds der Chemischen Industrie and from Deutsche Forschungsgemeinschaft.

\section{References}

1 R. Markby. H.W. Stemberg and $\mathrm{I}$. Wender, Chem. Ind., (1959) 1381.

2 R.S. Dickson and G. Wilkinson, J. Chem. Soc, (1964) 2699. 
3 M.D. Rausch and R.A. Genetti. J. Org. Chem.. 35 (1970) 3888: M.D. Rausch. Pure and Aoplied Chem.. 30 (1972) 528: S.A. Gardner. E.F. Tokas and M.D. Rausch. J. Organometal. Chem., 92 (1975) 69.

4 K.P.C. Vollhardt, J.E. Bercaw and R.G. Bergman. J. Amer. Chem. Soc., 96 (1974) 4996.

5 Y. Wakatsuki and H. Yamazaki. Chem. Commun. (1973) 280.

6 H. Bönnemann. Abstracts VIIth Intern. Conf. Coord. Chem.. 1975.

7 W.S. Lee and H.H. Brintzinger. J. Organometal. Chem., submitted.

8 H. Sakurai and J. Hayashi. J. Organometal. Chem., 39 (1972) 365: 70 (1974) 85.

9 M. Rosenblum. W.P. Giering, B. North and D. Wells, J. Organometal. Chem.. 28 (1971) C17.

0 S.A. Gardner, P.S. Andrews and M.D. Rausch, Inorg. Chem.. 12 (1973) 2396.

1 L.S. Meriwether, M.F. Leto. E.C. Colthup and G.W. Kennerly, J. Org. Chem.. 27 (1962) 3930 ; J.P. Collman. Accounts Chem. Res.. 1 (1968) 136.

2 G. Fachinetti and C. Floriani, Chem. Commun., (1974) 66.

3 K. Sonogashira and N. Hagihara, Bull. Chem. Soc. Japan, 39 (1966) 1178.

4 J.A. Pople. W.G. Schneider and H.J. Bernstein, High-Resolution Nuclear Magnetic Resonance, McGrawHill, N.Y., 1959. 